\title{
PENJADWALAN PRODUKSI DENGAN METODE CAMPBELL DUDEK SMITH (CDS) UNTUK MEMINIMUMKAN TOTAL WAKTU PRODUKSI (MAKESPAN)
}

\author{
Riko Ervil ${ }^{1)}$ Dela Nurmayuni ${ }^{2)}$ \\ Sekolah Tinggi Teknologi Industri Padang \\ delanurmayuni@yahoo.co.id
}

\begin{abstract}
Abstrak: Dalam proses produksinya beberapa operasi kerja memerlukan waktu proses yang sangat lama yang mengakibatkan besarnya waktu proses produksi perusahaan. Dampaknya ketika penjadwalan yang dilakukan kurang sesuai maka besarnya makespan dalam sistem produksi tersebut akan meningkat. Metode yang digunakan yaitu metode CDS (Campbell Dudek Smith), metode ini ditemukan oleh Campbell, Dudek, dan Smith yang merupakan pengembangan dari aturan Jhonson, untuk mendapatkan urutan pekerjaan metode CDS ini dapat menghasilkan $\mathrm{k}$ iterasi (alternatif urutan job) $\mathrm{k}=\mathrm{m}-1$ bertujuan untuk menghasilkan waktu produksi yang minimal. Hasil dan kesimpulan dengan menggunakan metode CDS diperoleh nilai makespan minimum dan penjadwalan yang optimal yang terdapat pada iterasi ketiga dengan nilai makespan sebesar 54 hari dan tidak ada pesanan yang terlambat.
\end{abstract}

Kata Kunci: Penjadwalan, CDS, Makespan

Abstrac: In the production process some work operations require a very long process time resulting in the amount of time the companys production process. The impact when scheduling is done less appropriate then size of makespan in the production system will increase.CDS (Campbell Dudek Smith), method discovered by Campbell, Dudek, and Smith which is a further development of rule Jhonson, to get the job CDS method this would yield $k$ iteration (alternative the job) $k=m-1$ was intended to reduce in this personal to cycle time production. The results and conclusions obtained the minimum makespan and optimal scheduling contained in iteration third an makespan value of 54 the day and there is no order overdue.

Keywords: Scheduling, CDS, Makespan

\section{PENDAHULUAN}

Dalam proses operasionalnya PT. Teluk Luas berproduksi berdasarkan make to order dengan kebijakan First Come First Serve (FCFS) sehingga proses produksi berjalan apabila sudah ada order/pesanan dari konsumen. Untuk sistem produksi yang diterapkan di perusahaan belum optimal, hal ini dapat dilihat dari proses penjemuran yang masih dilakukan hanya berdasarkan pengalaman dan intuisi saja, tidak adanya penjadwalan produksi yang disusun oleh perusahaan yang secara tidak langsung hal ini akan menjadi salah satu faktor yang akan menyebabkan perusahaan tertinggal dan tidak bisa bersaing dengan perusahaan sejenis(Ervil \& Nurmayuni, 2018).

Batasan masalah dalam penelitian ini adalah penelitian dan pengumpulan data dilakukan pada proses produksi di PT. Teluk Luas Padang, metode yang dipakai pada penelitian ini metode CDS, data besarnya waktu proses produksi untuk seluruh pekerjaan tanpa melihat line produksi, data jumlah pemesanan, data waktu penerimaan dan penyerahan produk, kapasitas produksi dan perpindahan semua material sudah termasuk ke dalam waktu proses 
produksi yang bersangkutan(Ervil, 2016). Tujuan yang ingin dicapai dalam penelitian ini adalah:

1. Meminimumkan total waktu produksi untuk menyelesaikan seluruh pekerjaan.

2. Membuat penjadwalan produksi yang optimal.

\section{METODE PENELITIAN}

\section{Lokasi dan Waktu Penelitian}

Penelitian ini berlokasi di PT. Teluk Luas Padang berlokasi di Jln. By Pass Kelurahan Tanjung Saba Pitameh, Kecamatan Lubuk Begalung Padang 25224, Sumatera Barat. Sedangkan waktu penelitian dilaksanakan pada bulan Januari 2018 sampai dengan Februari 2018.

\section{Data}

Data yang digunakan untuk penelitian ini adalah: waktu proses per-operasi kerja, jumlah banyak pesanan, data waktu penerimaan dan penyerahan produk. Adapun jenis data yang digunakan dalam penelitian ini adalah data sekunder. Data sekunder yaitu data yang diperoleh melalui media perantara atau secara tidak langsung yang berupa buku, catatan, bukti yang telah ada, atau arsip baik yang dipublikasikan maupun tidak dipublikasikan secara umum. Data yang dikumpulkan merupakan data-data yang diperoleh dari dokumen perusahaan dan hasil tanya jawab dengan pembimbing di lapangan.

\section{HASIL DAN PEMBAHASAN Waktu Proses Per-operasi Kerja}

Data waktu proses per-operasi kerja adalah sebagai berikut:

\section{Tabel 1}

Data Waktu Proses Per-operasi Kerja

\begin{tabular}{|c|c|c|c|c|c|c|c|c|}
\hline \multirow{2}{*}{ Job } & \multicolumn{7}{|c|}{ Waktu Proses Per-0perasi (Hari) } & \multirow{2}{*}{$\begin{array}{l}\text { Total Waktu } \\
\text { Proses (Hari) }\end{array}$} \\
\hline & 1 & 2 & 3 & 4 & 5 & 6 & 7 & \\
\hline 1 & 2 & 2 & 3 & 20 & 2 & 4 & 2 & 35 \\
\hline 2 & 1 & 1 & 2 & 17 & 1 & 2 & 1 & 25 \\
\hline 3 & 1 & 2 & 3 & 17 & 2 & 2 & 1 & 28 \\
\hline 4 & 1 & 1 & 2 & 16 & 1 & 1 & 1 & 23 \\
\hline 5 & 1 & 2 & 3 & 18 & 3 & 3 & 2 & 32 \\
\hline
\end{tabular}

Pengolahan data awal yaitu menghitung waktu proses per operasi kerja setiap pekerjaan. Terdapat 30 pekerjaan yang harus diselesaikan dengan waktu operasi pengerjaan pada masing-masing proses.

\section{Jumlah Banyak Pesanan}

Produksi crumb rubber selama ini dilakukan dengan memprioritaskan pesanan yang datang terlebih dahulu itu yang akan dikerjakan. Data pesanan crumb rubber yang diamati dalam penelitian ini untuk periode bulan Januari 2017 sampai bulan Juni 2017.

Tabel 2

Data Jumlah Banyak Pesanan

\begin{tabular}{|c|c|c|}
\hline Job & Tgl Pemesanan & Banyak Pesanan (Kg) \\
\hline 1 & 3 Januari 2017 & 806.400 \\
\hline 2 & 5 Januari 2017 & 201.600 \\
\hline 3 & 13 Januari 2017 & 302.400 \\
\hline 4 & 19 Januari 2017 & 100.800 \\
\hline 5 & 1 Februari 2017 & 403.200 \\
\hline
\end{tabular}

\section{Waktu Pemesanan dan Penyerahan Produk}

Pengumpulan data waktu pemesanan dan penyerahan produk crumb rubber data aktual yang diperoleh dari PT. Teluk Luas dengan mengacu pada order yang diterima dari konsumen di mulai dari bulan Januari 2017 sampai bulan Juni 2017.

\section{Tabel 3}

Data Waktu Pemesanan dan Penyerahan Crumb Rubber

\begin{tabular}{|c|c|c|}
\hline Job & Tgl Pemesanan & Tgl Penyerahan \\
\hline 1 & 3 Januari 2017 & 25 Februari 2017 \\
\hline 2 & 5 Januari 2017 & 21 Februari 2017 \\
\hline 3 & 13 Januari 2017 & 23 Februari 2017 \\
\hline 4 & 19 Januari 2017 & 21 Februari 2017 \\
\hline 5 & 1 Februari 2017 & 16 Maret 2017 \\
\hline
\end{tabular}

\section{Metode CDS (Campbell Dudek Smith)}

Data yang akan diolah menggunakan metode ini terdiri dari 30 job yang semuanya harus melalui 7 operasi kerja secara seri / berurutan untuk menjadi sebuah 
produk (crumb rubber). Perhitungan $\mathrm{k}$ iterasi : $k=m-1$. Jadi proses penjadwalan menggunakan metode CDS (Campbell Dudek Smith) sebanyak 6 kali.

1. P1 dengan P7 (Proses Pencucian dengan Proses Pengepakan)

\section{Tabel 4}

Perbandingan Waktu Proses Iterasi 1

\begin{tabular}{|c|c|c|}
\hline Job & P1 (Hari) & P7 (Hari) \\
\hline 1 & 2 & 2 \\
\hline 2 & 1 & 1 \\
\hline 3 & 1 & 1 \\
\hline 4 & 1 & 1 \\
\hline 5 & 1 & 2 \\
\hline
\end{tabular}

Dengan menggunakan aturan Johnson diperoleh urutan job sebagai berikut: $2-3-4-5-1$

2. $\mathrm{P} 1+\mathrm{P} 2$ dengan $\mathrm{P} 6+\mathrm{P} 7$ (Proses Pencucian + Proses Pencacahan dengan Proses Memasak + Proses Pengepakan)

Tabel 5

\section{Perbandingan Waktu Proses Iterasi 2}

\begin{tabular}{|c|c|c|}
\hline Job & P1+P2 (Hari) & P6+P7 (Hari) \\
\hline 1 & 4 & 6 \\
\hline 2 & 2 & 3 \\
\hline 3 & 3 & 3 \\
\hline 4 & 2 & 2 \\
\hline 5 & 3 & 5 \\
\hline
\end{tabular}

Tabel 7

Perbandingan Waktu Proses Iterasi 4

\begin{tabular}{|c|c|c|}
\hline Job & P1+P2+P3+P4 (Hari) & P4+P5+P6+P7 (Hari) \\
\hline 1 & 27 & 28 \\
\hline 2 & 21 & 21 \\
\hline 3 & 23 & 22 \\
\hline 4 & 20 & 19 \\
\hline 5 & 24 & 26 \\
\hline
\end{tabular}

Dengan menggunakan aturan Johnson diperoleh urutan job sebagai berikut: 4-2-3-5-1

5. $\mathrm{P} 1+\mathrm{P} 2+\mathrm{P} 3+\mathrm{P} 4+\mathrm{P} 5$ dengan $\mathrm{P} 3+$ $\mathrm{P} 4+\mathrm{P} 5+\mathrm{P} 6+\mathrm{P} 7$ (Proses Pencucian + Proses Pencacahan + Proses Penggilingan + Proses Penjemuran + Proses Peremahan
Dengan menggunakan aturan Johnson diperoleh urutan job sebagai berikut: 2-4-3-5-1

3. $\mathrm{P} 1+\mathrm{P} 2+\mathrm{P} 3$ dengan $\mathrm{P} 5+\mathrm{P} 6+\mathrm{P} 7$ (Proses Pencucian + Proses Pencacahan + Proses Penggilingan dengan Proses Peremahan + Proses Memasak + Proses Pengepakan)

Tabel 6

Perbandingan Waktu Proses Iterasi 3

\begin{tabular}{|c|c|c|}
\hline Job & P1+P2+P3 (Hari) & P5+P6+P7 (Hari) \\
\hline 1 & 7 & 8 \\
\hline 2 & 4 & 4 \\
\hline 3 & 6 & 5 \\
\hline 4 & 4 & 3 \\
\hline 5 & 6 & 8 \\
\hline
\end{tabular}

Dengan menggunakan aturan Johnson diperoleh urutan job sebagai berikut: 2-4-3-5-1

4. $\mathrm{P} 1+\mathrm{P} 2+\mathrm{P} 3+\mathrm{P} 4$ dengan $\mathrm{P} 4+\mathrm{P} 5+$ $\mathrm{P} 6+\mathrm{P} 7$ (Proses Pencucian + Proses Pencacahan + Proses Penggilingan + Proses Penjemuran dengan Proses Penjemuran + Proses Peremahan + Proses Memasak + Pros

dengan Proses Penggilingan + Proses Penjemuran + Proses Peremahan + Proses Memasak + Proses Pengepakan)

Tabel 8

Perbandingan Waktu Proses Iterasi 5

\begin{tabular}{|c|c|c|}
\hline Job & $\mathbf{P 1 + P 2 + P 3 + P 4 + P 5 ~ ( H a r i ) ~}$ & $\mathbf{P 3 + P 4 + P 5 + P 6 + P 7 ~ ( H a r i ) ~}$ \\
\hline 1 & 29 & 31 \\
\hline 2 & 22 & 23 \\
\hline 3 & 25 & 25 \\
\hline 4 & 21 & 21 \\
\hline 5 & 27 & 29 \\
\hline
\end{tabular}

Dengan menggunakan aturan Johnson diperoleh urutan job sebagai berikut: 4-2-3-5-1

6. $\mathrm{P} 1+\mathrm{P} 2+\mathrm{P} 3+\mathrm{P} 4+\mathrm{P} 5+\mathrm{P} 6$ dengan $\mathrm{P} 2+\mathrm{P} 3+\mathrm{P} 4+\mathrm{P} 5+\mathrm{P} 6+\mathrm{P} 7$ (Proses Pencucian + Proses Pencacahan + Proses Penggilingan + Proses Penjemuran + Proses Peremahan + Proses Memasak dengan Proses Pencacahan + Proses Penggilingan + Proses Penjemuran + Proses Peremahan + Proses Memasak + Proses Pengepakan) 
Tabel 9

Perbandingan Waktu Proses Iterasi 6

\begin{tabular}{|c|c|c|}
\hline Job & $\mathbf{P 1 + P 2 + P 3 + P 4 + P 5 + P 6 ~ ( H a r i ) ~}$ & $\mathbf{P 2 + P 3 + P 4 + P 5 + P 6 + P 7 ~ ( H a r i ) ~}$ \\
\hline 1 & 33 & 33 \\
\hline 2 & 24 & 24 \\
\hline 3 & 27 & 27 \\
\hline 4 & 22 & 22 \\
\hline 5 & 30 & 31 \\
\hline
\end{tabular}

Dengan menggunakan aturan Johnson diperoleh urutan job sebagai berikut: 4-2-3-5-1

\section{Perhitungan Makespan Metode CDS} $4-5-1$

Urutan pekerjaannya adalah : $2-3-$

Tabel 10

Waktu Proses Per-Operasi

\begin{tabular}{|c|c|c|c|c|c|c|}
\hline \multirow{2}{*}{ Job } & \multicolumn{7}{|c|}{ Waktu Proses Per Operasi (Hari) } \\
\cline { 2 - 7 } & $\mathbf{1}$ & $\mathbf{2}$ & $\mathbf{3}$ & $\mathbf{4}$ & $\mathbf{5}$ & $\mathbf{6}$ \\
\hline 2 & 1 & 1 & 2 & 17 & 1 & 2 \\
\hline 3 & 1 & 2 & 3 & 17 & 2 & 2 \\
\hline 4 & 1 & 1 & 2 & 16 & 1 & 1 \\
\hline 5 & 1 & 2 & 3 & 18 & 3 & 3 \\
\hline 1 & 2 & 2 & 3 & 20 & 2 & 4 \\
\hline
\end{tabular}

1. Perhitungan Makespan Untuk Proses Pencucian

Tabel 11

Perhitungan Makespan Untuk Proses

Pencucian

\begin{tabular}{|c|c|c|r|}
\hline Job & Star Time (Hari) & Processing Time (Hari) & Completion T \\
\hline 2 & 0 & 1 & 1 \\
\hline 3 & 1 & 1 & 2 \\
\hline 4 & 2 & 1 & 3 \\
\hline 5 & 0 & 1 & 1 \\
\hline 1 & 3 & 2 & 5 \\
\hline
\end{tabular}

2. Perhitungan Makespan Untuk Proses Pencacahan

Tabel 12

Perhitungan Makespan Untuk Proses Pencacahan

\begin{tabular}{|c|c|c|r|}
\hline Job & Star Time (Hari) & Processing Time (Hari) & Completion T \\
\hline 2 & 1 & 1 & 2 \\
\hline 3 & 2 & 2 & 4 \\
\hline 4 & 3 & 1 & 4 \\
\hline 5 & 1 & 2 & 3 \\
\hline 1 & 14 & 2 & 16 \\
\hline
\end{tabular}

3. Perhitungan Makespan Untuk Proses Penggilingan

Tabel 13

Perhitungan Makespan Untuk Proses

Penggilingan

\begin{tabular}{|c|c|c|c|}
\hline Job & Start Time (Hari) & Processing Time (Hari) & Completion Time (Hari) \\
\hline 2 & 2 & 2 & 4 \\
\hline 3 & 4 & 3 & 7 \\
\hline 4 & 4 & 2 & 6 \\
\hline 5 & 3 & 3 & 6 \\
\hline 1 & 16 & 3 & 19 \\
\hline
\end{tabular}

4. Perhitungan Makespan Untuk Proses Penjemuran

Tabel 14

Perhitungan Makespan Untuk Proses Penjemuran

\begin{tabular}{|c|c|c|c|}
\hline Job & Start Time (Hari) & Processing Time (Hari) & Completion Time (Hari) \\
\hline 2 & 4 & 17 & 21 \\
\hline 3 & 7 & 17 & 24 \\
\hline 4 & 6 & 16 & 22 \\
\hline 5 & 6 & 18 & 24 \\
\hline 1 & 19 & 20 & 39 \\
\hline
\end{tabular}

5. Perhitungan Makespan Untuk Proses Peremahan

Tabel 15

Perhitungan Makespan Untuk Proses

Peremahan

\begin{tabular}{|c|c|c|c|}
\hline Job & Start Time (Hari) & Processing Time (Hari) & Completion Time (Hari) \\
\hline 2 & 21 & 1 & 22 \\
\hline 3 & 24 & 2 & 26 \\
\hline 4 & 22 & 1 & 23 \\
\hline 5 & 24 & 3 & 27 \\
\hline 1 & 39 & 2 & 41 \\
\hline
\end{tabular}

6. Perhitungan Makespan Untuk Proses Memasak

Tabel 16

Perhitungan Makespan Untuk Proses

Memasak

\begin{tabular}{|c|c|c|c|}
\hline Job & Start Time (Hari) & Processing Time (Hari) & Completion Time (Hari) \\
\hline 2 & 22 & 2 & 24 \\
\hline 3 & 26 & 2 & 28 \\
\hline 4 & 23 & 1 & 24 \\
\hline 5 & 27 & 3 & 30 \\
\hline 1 & 41 & 4 & 45 \\
\hline
\end{tabular}

7. Perhitungan Makespan Untuk Proses Pengepakan

Tabel 17

Perhitungan Makespan Untuk Proses Pengepakan

\begin{tabular}{|c|c|c|c|c|}
\hline Job & Start Time (Hari) & Processing Time (Hari) & Completion Time (Hari) & Job Late (Hari \\
\hline 2 & 24 & 1 & 25 & -22 \\
\hline 3 & 28 & 1 & 29 & -12 \\
\hline 4 & 24 & 1 & 25 & -8 \\
\hline 5 & 30 & 2 & 32 & -11 \\
\hline 1 & 45 & 2 & 47 & 3 \\
\hline
\end{tabular}

Dari hasil perhitungan menggunakan metode CDS diperoleh nilai makespan yaitu 
47 hari. Dan tidak ada pekerjaan yang terlambat.

\section{Metode FCFS (First Come First Serve)}

Metode pengolahan data yang digunakan oleh perusahaan yaitu FCFS (First Come First Serve) adalah order yang terlebih dahulu masuk akan diproses terlebih dahulu.

Tabel 18

Perhitungan Metode FCFS

\begin{tabular}{|c|c|c|c|c|c|}
\hline \multirow{2}{*}{ Job } & \multicolumn{5}{|c|}{ Waktu Proses Per-Operasi ( Hal } \\
\cline { 2 - 6 } & $\mathbf{1}$ & $\mathbf{2}$ & $\mathbf{3}$ & $\mathbf{4}$ & $\mathbf{5}$ \\
\hline 1 & 2 & 2 & 3 & 20 & 2 \\
\hline 2 & 1 & 1 & 2 & 17 & 1 \\
\hline 3 & 1 & 2 & 3 & 17 & 2 \\
\hline 4 & 1 & 1 & 2 & 16 & 1 \\
\hline 5 & 1 & 2 & 3 & 18 & 3 \\
\hline
\end{tabular}

Berdasarkan pengolahan data diatas didapatkan makespan sebesar 76 hari yang didapat dari total waktu kumulatif dari masing-masing job.

\section{KESIMPULAN}

Pada penjadwalan produksi dengan metode CDS didapatkan nilai makespan sebesar 47 hari, sedangkan dengan metode FCFS yang digunakan oleh perusahaan saat ini didapat nilai makespan sebesar 76 hari. Jadi metode CDS mempunyai penyelesaian produksi tercepat dari pada metode FCFS yang digunakan oleh perusahaan. Penjadwalan produksi dengan menggunakan metode CDS menghasilkan enam iterasi, dari keenam iterasi hanya pada iterasi ketiga yang tidak terdapat $j o b$ yang terlambat. Berikut urutan kerja yaitu: job $2-j o b 3-j o b 4-j o b 5-$ job 1 dengan total waktu produksinya berlangsung selama 47 hari untuk menyelesaikan seluruh pesanan (job).

\section{DAFTAR PUSTAKA}

Christianta, Yudit dan Theresia Sunarni. Jurnal ISBN 979-26-0255-0. Usulan Penjadwalan Produksi Dengan Metode Campbell Dudek And Smith (Studi Kasus Pada PT. PAN Panel Palembang). Teknik Industri
Sekolah Tinggi Teknik Musi. Palembang. 2012.

Hamman, Muhammad Khasanul. Skripsi. Penjadwalan Produksi Flow Shop Untuk Meminimalkan Makespan Dengan Metode Campbell, Dudek, And Smith (CDS), Metode Palmer, Metode Dannenbring, Dan Metode Ignall-Scharge (Studi Kasus Di CV. Bonjor Jaya, Klaten). Universitas Islam Negeri Sunan Kalijaga. Yogyakarta. 2015.

Herlina. Skripsi. Penjadwalan Produksi Dengan Metode N-Job M-Mesin Untuk Meminimalisasi Makespan Pada PT. Harapan Widyatama Pertiwi Untuk Pembuatan Pipa PVC. Fakultas Teknik. UBN. 2006.

Kurnia, R. Yasra, V. M. Afma. Jurnal ISSN Cetak: 2301-7244. Penjadwalan Produksi Dengan Menggunakan Metode Campbell, Dudek \& Smith Pada Mesin Laser Marking Jenis Evertech Untuk Meminimalisasi Makespan. Univ. Riau Kepulauan Batam. Kepulauan Riau. 2013.

Nasution, Arman Hakim. Perencanaan dan Pengendalian Produksi. Guna Widya. Surabaya. 2003.

Ervil, R. (2016). Perbandingan Nilai Overall Equipment Effectiveness (Oee) Mesin Packer Lama Dan Mesin Packer Baru Pada Packing Plant Indarung (Ppi) Pt. Semen Padang. Saint Dan Teknologi STTIND Padang, 16(2).

Ervil, R., \& Nurmayuni, D. (2018). Penjadwalan Produksi Dengan Metode Campbell Dudek Smith (Cds) Untuk Meminimumkan Total Waktu Produksi (Makespan). Saint Dan Teknologi STTIND Padang, 18(1), 13-17.

Tannady, Hendy dan Steven, Andrew Verrayo Limas. Jurnal Teknik Industri. Vol X. No. 1. Januari 2015. Solusi Urutan Pengerjaan Job Yang Tepat Dengan Metode Campbell-Dudek-Smith (CDS). 